\title{
A Comparative Evaluation of Dotted Raster- Stereography and Feature-Based Techniques for Automated Face Recognition
}

\author{
Muhammad Wasim \\ Department of Computer Science \\ Usman Institute of Technology \\ Karachi, Pakistan
}

\author{
S. Talha Ahsan \\ Department of Electrical Engineering \\ Usman Institute of Technology \\ Karachi, Pakistan
}

\author{
Lubaid Ahmed, Syed Faisal Ali, \\ Fauzan Saeed \\ Department of Computer Science \\ Usman Institute of Technology \\ Karachi, Pakistan
}

\begin{abstract}
Automated face recognition systems are fast becoming a need for security-related applications. Development of a fool-proof and efficient face recognition system is a challenging domain for researchers. This paper presents comparative evaluation of two candidate techniques for automated face recognition application, viz. dotted Rasterstereography and feature-based system. The relevant performance parameters - accuracy, precision, sensitivity and specificity - measured for the two techniques using IPRL Database of images are reported. The results suggest that dotted Raster-stereography based face recognition system has better accuracy, precision, sensitivity and specificity, and hence is a preferred choice as compared with feature-based system for such sensitive applications where high face recognition accuracy is required. On the other hand, feature-based technique is faster in terms of the training and testing times required. Hence such applications where volume of face recognition work is large and high speed is required with some compromise in accuracy being acceptable then feature-based technique may also be the technique of choice.
\end{abstract}

Keywords-Raster-stereography; dotted raster-stereography; feature based; face recognition; IPRL

\section{INTRODUCTION}

In today's world where computer- and IT-based systems are being used everywhere for different applications, user authentication is a key requirement to ensure security of these systems and applications. Implementing system protection with user ID and password is a common practice in e-mail, online banking and ATM systems. However, if password is hacked or stolen, then these apparently secure systems become vulnerable to unauthorized access. Long and hard passwords are not easy to remember; similarly the probability to guess short and simple passwords is high. Hence for these reasons, password protected systems are not very secure.
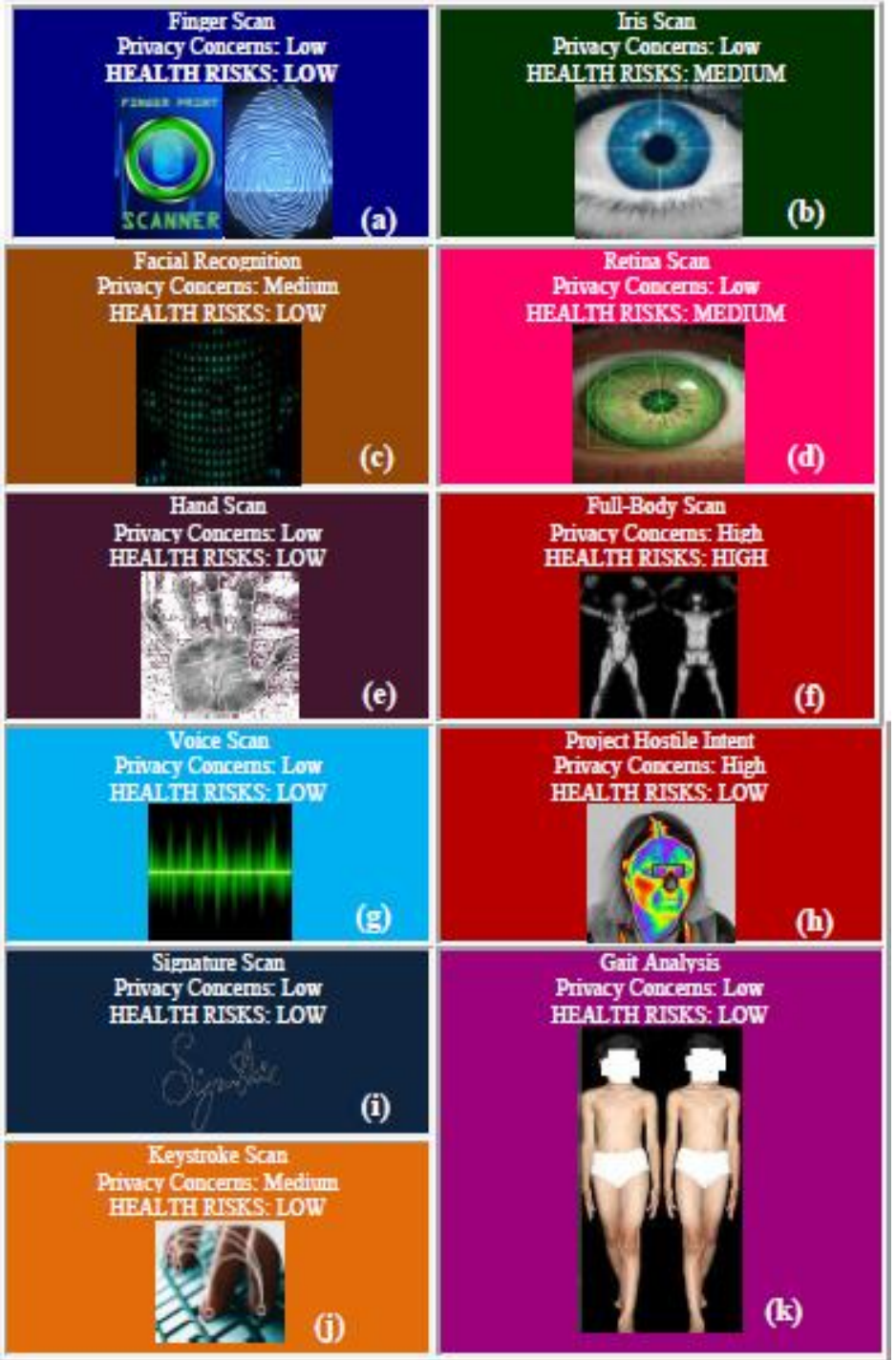

Fig. 1. Different biometric systems (a) Finger scan (b) Iris scan (c) Facial recognition (d) Retina scan (e) Hand scan (f) Full body scan (g) Voice scan (h) Project hostile intent (i) Signature scan (j) Keystroke scan and (k) Gait analysis. 
In recent times, biometric-based identification or recognition is being incorporated in security technologies. A biometric feature is a distinctive and computable attribute of a human being that can be used to authenticate an individual. A biometric system is capable to compute both physiological and behavioral patterns of a person for the purpose of recognition [1]. The physiological domain is based on measurement or scan of a part of the human body, e.g. face [2], finger [3], hand [4], iris and retina [5-6]. On the other hand, the behavioral domain is based on measurement from some specific action of a person, e.g., gait characteristics, keystroke scan, signature scan, voice scan [1] and hostile intent [7]. Each of these biometric techniques has its own privacy concern and health risk [8], as shown in Fig. 1. Face recognition system [9] is a recommended technique for person identification as compared with the other biometric systems.

\section{FACE RECOGNITION SYSTEMS}

\section{A. Background}

Face recognition or identification is a process of matching a face from all available face-images in the system database [9]. Facial identification is a stereo-photogrammetric system, which has less health related issues. It is non-contact, nondestructive and radiation free technique [10]. A face can be recognized even with partial facial information, which can be captured with inexpensive cameras. From the last couple of years, automated face recognition, being one of the prominent applications of facial image analysis has become an attractive domain for researchers.

\section{B. Literature Review}

The preliminary work related to human facial identification system described the domain of psychology [11] and engineering [12]. Kelly [13] commenced research for automated facial identification; later Kanade [14] continued the significant work in the same domain. Darwin [15] and Galton [16] described facial recognition technique as a biometric system. Eigenfaces [17], [18] as well as Fisher faces [19]-[21] techniques recognized as a reliable mechanism especially for huge datasets. On the other hand a graphmatching method was one of a useful technique related to feature based method [22], [23]. Face recognition and tracking system in videos are now very interesting area for the last few years [24].

Sun et al. [25] used a specialized form of machine learning based on high level face features to identify human faces. Researchers have discussed ways to improve the performance of face recognition techniques [26]-[32]. In [33], [34], classification-based methods were used for the purpose of face identification. The performance of this technique was good. A component-based technique for face recognition is discussed in [35]. $\mathrm{Xu}$ et al. [36] specified about the change in performance of face recognition techniques with change of environment, lighting and expression of faces.

\section{Face Recognition Techniques}

Facial recognition systems are now one of more attractive and popular area for the researchers. The techniques required to recognize human faces can be categorized in three diverse approaches, mainly known as: i) Holistic; ii) Feature-based; and iii) Hybrid (Fig. 2).

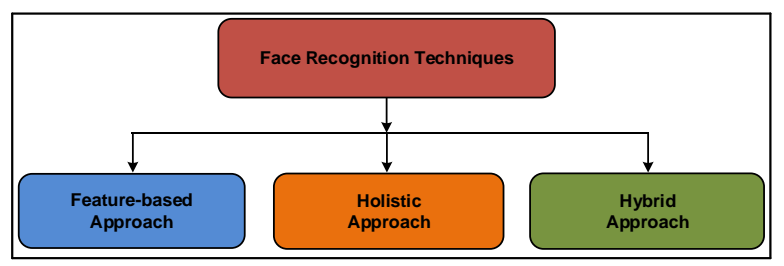

Fig. 2. Categorization of face-recognition techniques.

In this paper, two approaches of machine-based face recognition have been discussed: i) dotted Raster-stereography [37]; ii) feature-based [38]. Dotted Raster-stereography is a holistic approach, in which identification takes place on the basis of global attributes i.e. curvature patterns of human face in term of pixels and their corresponding coordinate values. In featured-based technique, identification is performed on the basis of local features obtained from the human face (noseeyes-mouth). The research work presented here compares, for these two techniques, the performance measures of accuracy, precision, sensitivity and specificity, using the Image Processing Research Lab (IPRL) database of images.

\section{IMAGE PROCESSING RESEARCH LAB (IPRL) DATABASE OF IMAGES}

The images of IPRL database were recorded in Image Processing Research Laboratory (IPRL) at Usman Institute of Technology (UIT), Karachi, Pakistan. This database contains a variety of facial images recorded with different illumination, facial orientation and expression of human faces. Each facial image has its corresponding facial curvatures as well in term of dotted patterns (Fig. 3). This database currently holds 800 human face images with five orientations (frontal, left, right, up and down). It also holds the facial key features of these faces in the form of dots. To describe face recognition based on dotted raster-stereography mean (M) and Gaussian (G) are obtained as decision parameters. Table I presents a snapshot of IPRL database. Fig. 3 shows a snap shot of IPRL database images.

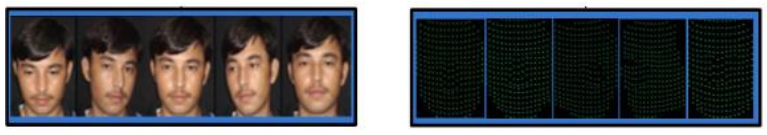

Fig. 3. IPRL Database sample (left: original facial images, right: their dotted-curvature-patterns).

TABLE I. SNAPSHOT OF IPRL DATABASE

\begin{tabular}{|l|l|}
\hline \multicolumn{1}{|c|}{ Attributes } & \multicolumn{1}{|c|}{ Description } \\
\hline $\begin{array}{l}\text { Total no. of human } \\
\text { faces }\end{array}$ & 800 human faces (both male \& female) \\
\hline Classifications & $\begin{array}{l}4000 \text { human faces, 4000 facial } \\
\text { curvatures }\end{array}$ \\
\hline Nature of images & Static \\
\hline $\begin{array}{l}\text { Single or Multiple } \\
\text { faces }\end{array}$ & Single \\
\hline Attributes of images & Colored \\
\hline
\end{tabular}




\begin{tabular}{|l|l|}
\hline Resolution & Various \\
\hline Facial Pose & $\begin{array}{l}\text { Frontal, left }\left(-15^{\circ}\right) \text {, right }\left(+15^{\circ}\right) \text {, down } \\
\left(-15^{\circ}\right) \text {, up }\left(+15^{\circ}\right)\end{array}$ \\
\hline Facial Expression & N/A \\
\hline Illumination & N/A \\
\hline Light Condition & Dark Illumination \\
\hline Accessories & $\begin{array}{l}\text { With and without Beard, with and } \\
\text { without glasses }\end{array}$ \\
\hline 3D Data & N/A \\
\hline
\end{tabular}

\section{DOTTED RASTER-STEREOGRAPHY TECHNIQUE}

The proposed face recognition technique using dotted Raster-stereography consists of three basic steps: registration of face, identification of face; and recognition of face as given in the flow chart shown in Fig. 4.

Dotted raster grid, consisting of green color-dots of equal spacing $(0.6 \mathrm{~mm})$, was projected on human face. Because of the curved surface of human face, distortions were created and recorded in term of coordinate values. Fundamental curvatures $\kappa_{1}$ and $\kappa_{2}$ were calculated respectively, which are the main source of curvatures mean (M) and Gaussian (G). These dotted curvature patterns in Table II are easily picks using image processing algorithms. Pixels and their corresponding coordinate values of each dot in curved patterns are representing the face curvature patterns of each person.

\section{A. Mathematical Model of Dotted Raster-stereography \\ Technique}

Human faces can be mapped as curved surfaces, curvature patterns were generated when dotted grid (raster) projected on facial surface of human using multimedia projector. Using a digital camera these curvature patterns were recorded and use as an input for the computer system. Designed algorithm was used to find the pixel and corresponding coordinate values in term of $(x, y)$. Using the developed mathematical model the horizontal and vertical curvatures ' $\kappa_{1}$ ' and ' $\kappa_{2}$ ' were calculated. These two facial curvatures were used to calculate decision parameters mean $(\mathrm{M})$ and gaussian $(\mathrm{G})$ curvatures. In our work $\mathrm{M}$ and $\mathrm{G}$ were the main source of face recognition.

\section{B. Fundamental Curvatures $(\kappa 1, \kappa 2)$}

The fundamental curvatures ' $\kappa_{1}$ ' and ' $\kappa_{2}$ ' represents the horizontal and vertical curvatures simultaneously of human face in the face-recognition system described in this work (Fig. 5).

\section{Mean and Gaussian Curvatures $(M, G)$}

Mean and Gaussian facial curvatures can be obtained using equations (1) and (2), while $\kappa \rho=1$, where ' $\rho$ ' is the radius of curve generated by facial curvatures of human face.

$$
\begin{gathered}
\text { Mean }=\frac{\kappa_{1}+\kappa_{2}}{2} \ldots \ldots .(1) \\
\text { Gaussian }=\kappa_{1} \times \kappa_{2} \ldots \ldots(2)
\end{gathered}
$$

There are four basic types of curvatures of a small surface element [39] as shown in Fig. 4 and the fundamental curvatures $\left(\kappa_{1}\right.$ and $\left.\kappa_{2}\right)$ decision is described.

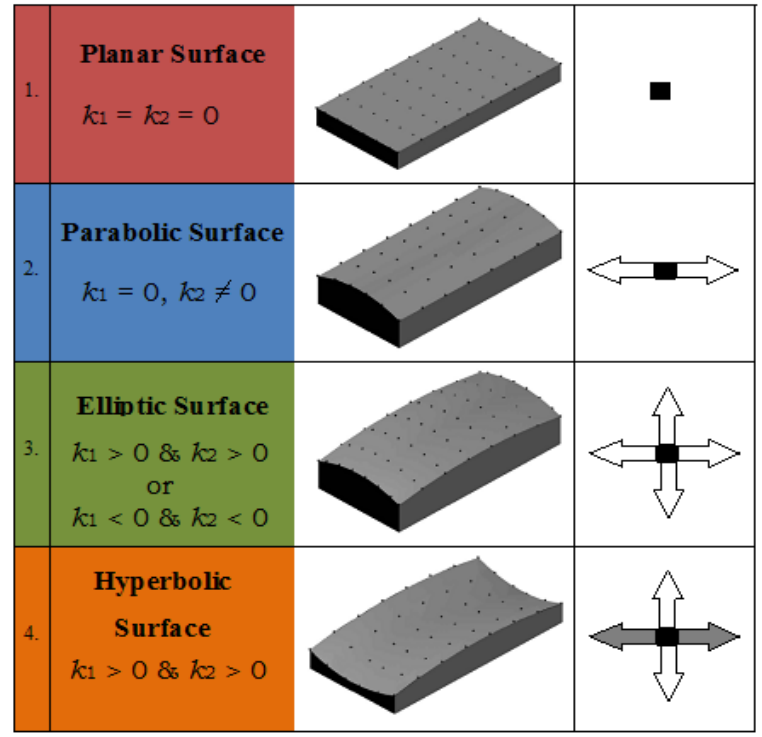

Fig. 4. Four basic types of curvatures

The following Fig. 5 shows the flow of proposed system technique.

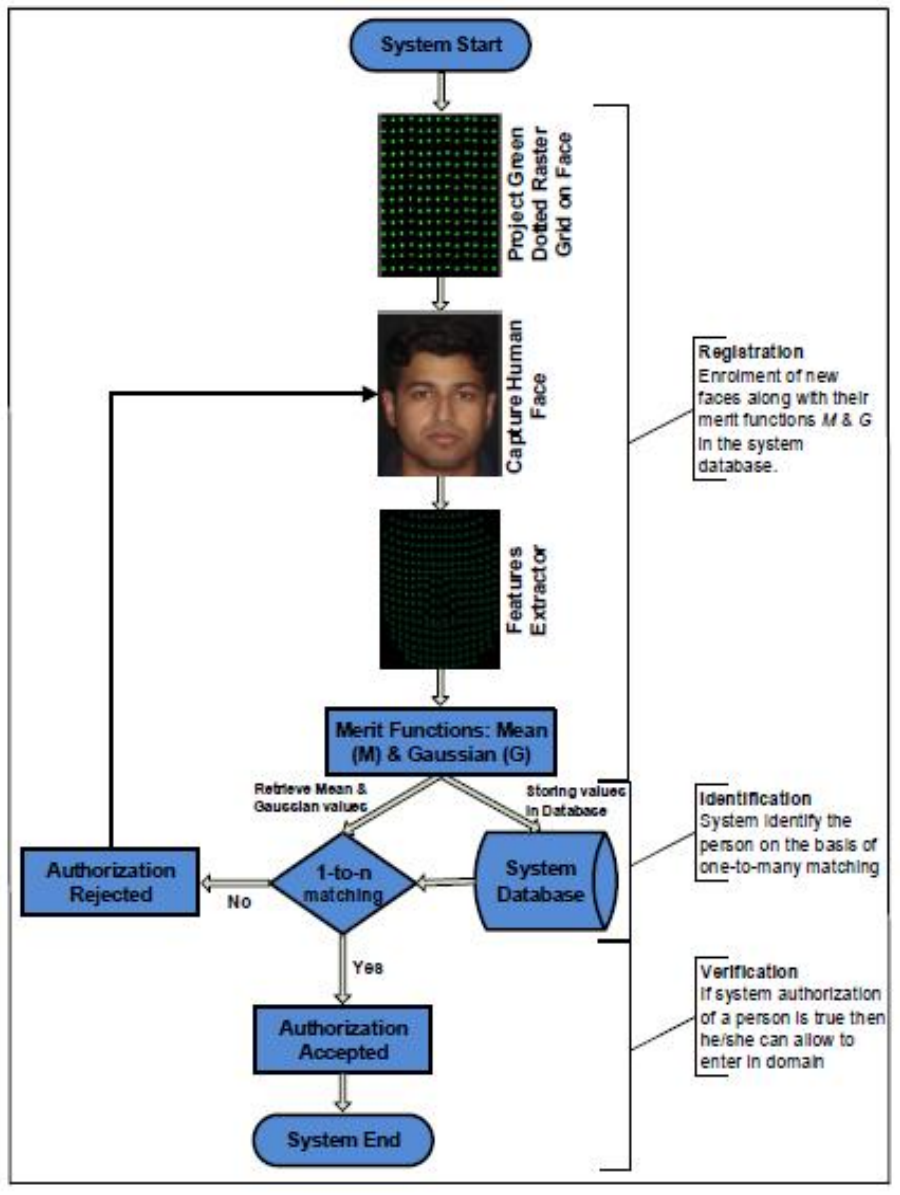

Fig. 5. Flow diagram of dotted Raster-stereography system. 


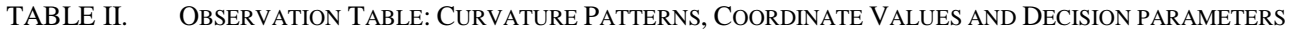

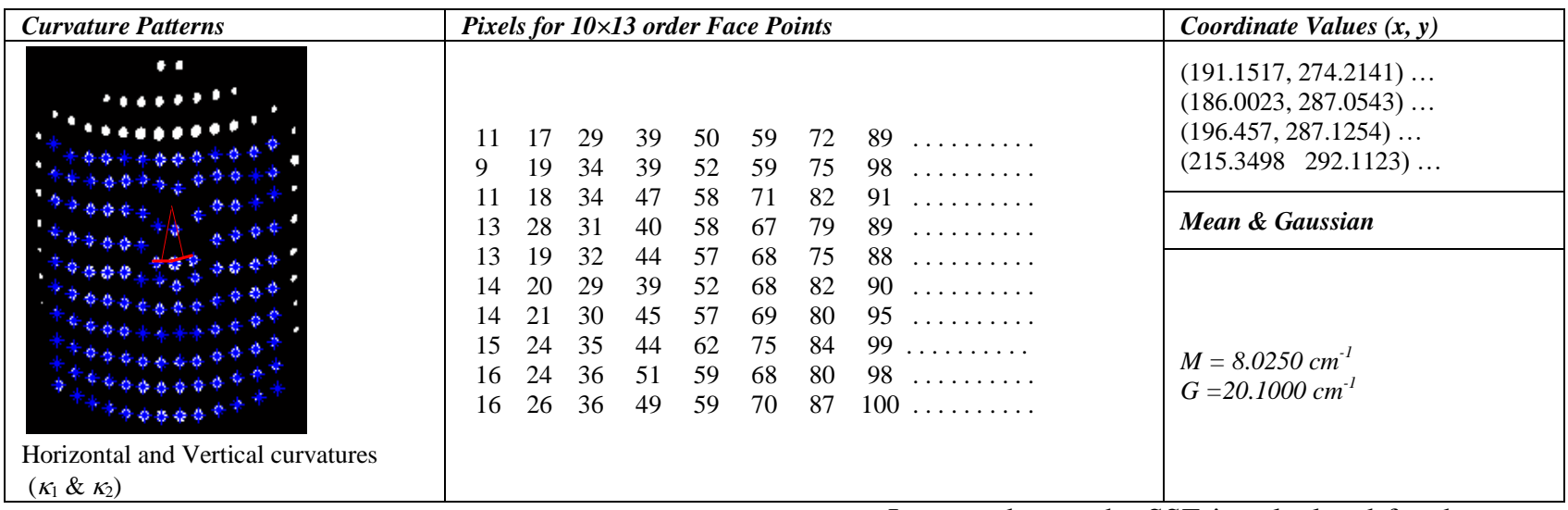

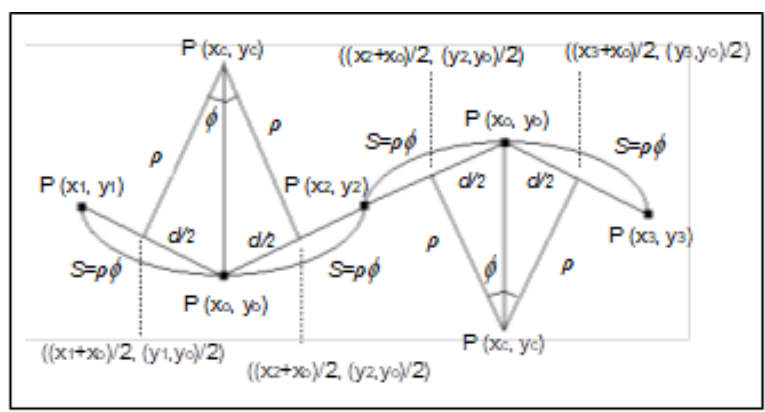

Fig. 6. Mathematics of Raster-stereography.

\section{Mathematics of Curvature Extraction}

In our mathematical model, ' $d$ ' was the small gap (distance) between two points in the original grid. When this raster grid was projected on the face of human, grid were distorted and provided the facial curvature information of human face. When distorted grid generated linear spacing ' $d$ ' is converted into arc length ' $s$ ' (Fig. 6). The study of this arc length provided the detail of facial curvatures of human face. From the geometry of Fig. 6, it is obtained that angular distance $=\kappa s$ and $\kappa \rho=1$ ), the result for curvatures $\kappa$, we obtained:

$$
\kappa \approx \pm \frac{1}{s} \sqrt{24\left(1-\frac{d}{s}\right)}
$$

$\kappa_{1}$ and $\kappa_{2}$ are the horizontal and the vertical curvatures.

\section{FEATURE-BASED TECHNIQUE}

Feature-Based technique described in this work is based on core features selection of the human face i.e. mouth, nose and eyes. In this technique, edge density (ED) and sum of square for error (SSE) are the two parameters required to recognize a face. In the first step, ED is calculated. An ED can be described as it is an edge, which belongs to the boundaries among two dissimilar classes of intensity. Mathematically ED is a ratio between perimeter (E) and area (A) as given in Fig. 7. This relation is described in the following equation 4 .

$$
\mathrm{ED}=\frac{\mathrm{E}}{\mathrm{A}}
$$

In second step, the SSE is calculated for the purpose of face recognition [39].

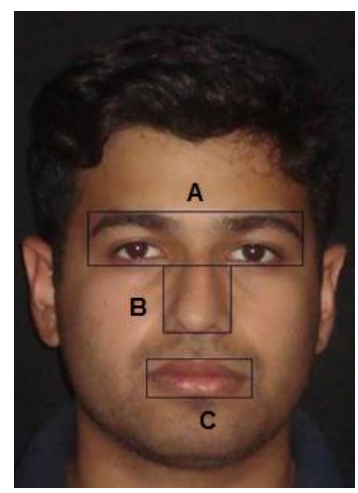

Fig. 7. The feature-based approach is based on edge density.

\section{A. Mathematical Model of Feature Based Technique}

Edge density $(E D)$ is a ratio between perimeter $(E)$ and the area $\left(A_{e}\right)$ where perimeter $\mathrm{E}$ is the average of perimeters $\mathrm{A}, \mathrm{B}$ and $\mathrm{C} ; \mathrm{A}_{\mathrm{e}}$ is the area of eye rectangle, whose perimeter is $\mathrm{A}$.

$$
\mathrm{ED}=\frac{\mathrm{E}}{\mathrm{A}_{\mathrm{e}}}
$$

$$
\text { where } \begin{aligned}
\mathrm{E} & =\frac{(\mathrm{A}+\mathrm{B}+\mathrm{C})}{3} \\
\mathrm{~A} & =\text { perimeter of eye }=2\left(\mathrm{~L}_{\mathrm{e}}+\mathrm{W}_{\mathrm{e}}\right) \\
\mathrm{B} & =\text { perimeter of nose }=2\left(\mathrm{~L}_{\mathrm{n}}+\mathrm{W}_{\mathrm{n}}\right) \\
\mathrm{C} & =\text { perimeter of mouth }=2\left(\mathrm{~L}_{\mathrm{m}}+\mathrm{W}_{\mathrm{m}}\right)
\end{aligned}
$$

$\mathrm{L}_{\mathrm{e}}, \mathrm{L}_{\mathrm{n}}$ and $\mathrm{L}_{\mathrm{l}}$ are the length of selected rectangular of eyes, nose and mouth.

$$
\text { Area }=A_{e}=L_{e} \times W_{e}
$$

\section{B. Calculation of Sum of Square for Error}

Table III shows the calculation of sum of square for error (SSE) for sample face of IPRL-UIT-2015061-01 from IPRL Database. 
TABLE III. CALCULATION OF SUM OF SQUARE FOR ERROR

\begin{tabular}{|c|c|c|c|c|c|c|}
\hline $\mathbf{x}$ & $\mathbf{y}$ & $\mathbf{x}-\mathbf{M}_{\mathbf{x}}$ & $\mathbf{y}-\mathbf{M}_{\mathbf{y}}$ & $\left(\mathbf{x}-\mathbf{M}_{\mathbf{x}}\right)^{\mathbf{2}}$ & $\left(\mathbf{y}-\mathbf{M}_{\mathbf{y}}\right)^{\mathbf{2}}$ & $\left(\mathbf{x}-\mathbf{M}_{\mathbf{x}}\right)\left(\mathbf{y}-\mathbf{M}_{\mathbf{y}}\right)$ \\
\hline 67 & 181 & -106.41 & -93.08 & 11323.0881 & 8663.8864 & 9904.6428 \\
\hline 262 & 182 & 88.59 & -92.08 & 7848.1881 & 8478.7264 & -8157.3672 \\
\hline 262 & 231 & 88.59 & -43.08 & 7848.1881 & 1855.8864 & -3816.4572 \\
\hline 68 & 231 & -105.41 & -43.08 & 11111.2681 & 1855.8864 & 4541.0628 \\
\hline 120 & 316 & -53.41 & 41.92 & 2852.6281 & 1757.2864 & -2238.9472 \\
\hline 197 & 231 & 23.59 & -43.08 & 556.4881 & 1855.8864 & -1016.2572 \\
\hline 197 & 292 & 23.59 & 17.92 & 556.4881 & 321.1264 & 422.7328 \\
\hline 136 & 292 & -37.41 & 17.92 & 1399.5081 & 321.1264 & -670.3872 \\
\hline 120 & 316 & -53.41 & 41.92 & 2852.6281 & 1757.2864 & -2238.9472 \\
\hline 216 & 315 & 42.59 & 40.92 & 1813.9081 & 1674.4464 & 1742.7828 \\
\hline 316 & 351 & 142.59 & 76.92 & 20331.9081 & 5916.6864 & 10968.0228 \\
\hline 120 & 351 & -53.41 & 76.92 & 2852.6281 & 5916.6864 & -4108.2972 \\
\hline $\mathbf{2 0 8 1}$ & $\mathbf{3 2 8 9}$ & $\mathbf{0 . 0 8}$ & $\mathbf{0 . 0 4}$ & $\mathbf{7 1 3 4 6 . 9 1 7 2}$ & $\mathbf{4 0 3 7 4 . 9 1 6 8}$ & $\mathbf{5 3 3 2 . 5 8 3 6}$ \\
\hline
\end{tabular}

Mean of $\mathrm{x}=\mathrm{M}_{\mathrm{x}}=173.41$

Mean of $\mathrm{y}=\mathrm{M}_{\mathrm{y}}=274.08$

Variance of $\mathrm{x}=\operatorname{var}(\mathrm{x})=5945.57$

Variance of $\mathrm{y}=\operatorname{var}(\mathrm{y})=3364.57$

Co - variance $=\operatorname{cov}(\mathrm{x}, \mathrm{y})=484.78$

$$
\frac{\operatorname{cov}(x, y)}{\operatorname{var}(x)}=0.0815
$$

$\operatorname{SSE}=(n-1)\left[\operatorname{var}(y)-\frac{\operatorname{cov}(x, y)}{\operatorname{var}(x)}\right]=370.0937$

\section{RESULTS}

A. Results of Dotted Raster-stereography and Feature-Based Technique

Table IV shows the results of dotted Raster-stereography and feature-based techniques.

B. Accuracy, Precision, Sensitivity and Specificity of Dotted Raster-stereography and Feature-Based Systems

This dotted raster-stereography technique is based on Mean and Gaussian curvatures. Both mean and Gaussian curvatures are based on two fundamental curvatures $\kappa_{1}$ and $\kappa_{2}$, as shown in Table V.

TABLE IV. RESUlts OF DOTTED RASTER-STEREOGRAPHY AND FEATURE-BASED TECHNIQUES

\begin{tabular}{|c|c|c|c|c|c|c|c|}
\hline \multirow[b]{2}{*}{$\begin{array}{l}\text { S. } \\
\text { No }\end{array}$} & \multirow[b]{2}{*}{ Face ID } & \multirow[b]{2}{*}{ Sample Faces } & \multicolumn{2}{|c|}{$\begin{array}{c}\text { Raster-stereography } \\
\text { Technique } \\
\end{array}$} & \multirow[b]{2}{*}{ Sample Faces } & \multicolumn{2}{|c|}{ Feature-Based Technique } \\
\hline & & & $\begin{array}{c}\text { Mean } \\
(\mathrm{M}) \\
\mathrm{cm}^{-1}\end{array}$ & $\begin{array}{c}\text { Gaussian }(G) \\
\mathrm{cm}^{-1}\end{array}$ & & $\begin{array}{c}\text { Edge } \\
\text { Density } \\
(\mathrm{ED}) \\
\mathrm{cm}^{-1}\end{array}$ & $\begin{array}{c}\text { Sum of } \\
\text { Square Error } \\
\text { (SSE) }\end{array}$ \\
\hline 1 & $\begin{array}{l}\text { IPRL-UIT- } \\
\text { 2015061-01 }\end{array}$ & & 03.0500 & 06.0600 & & 0.0355 & 370.0937 \\
\hline
\end{tabular}




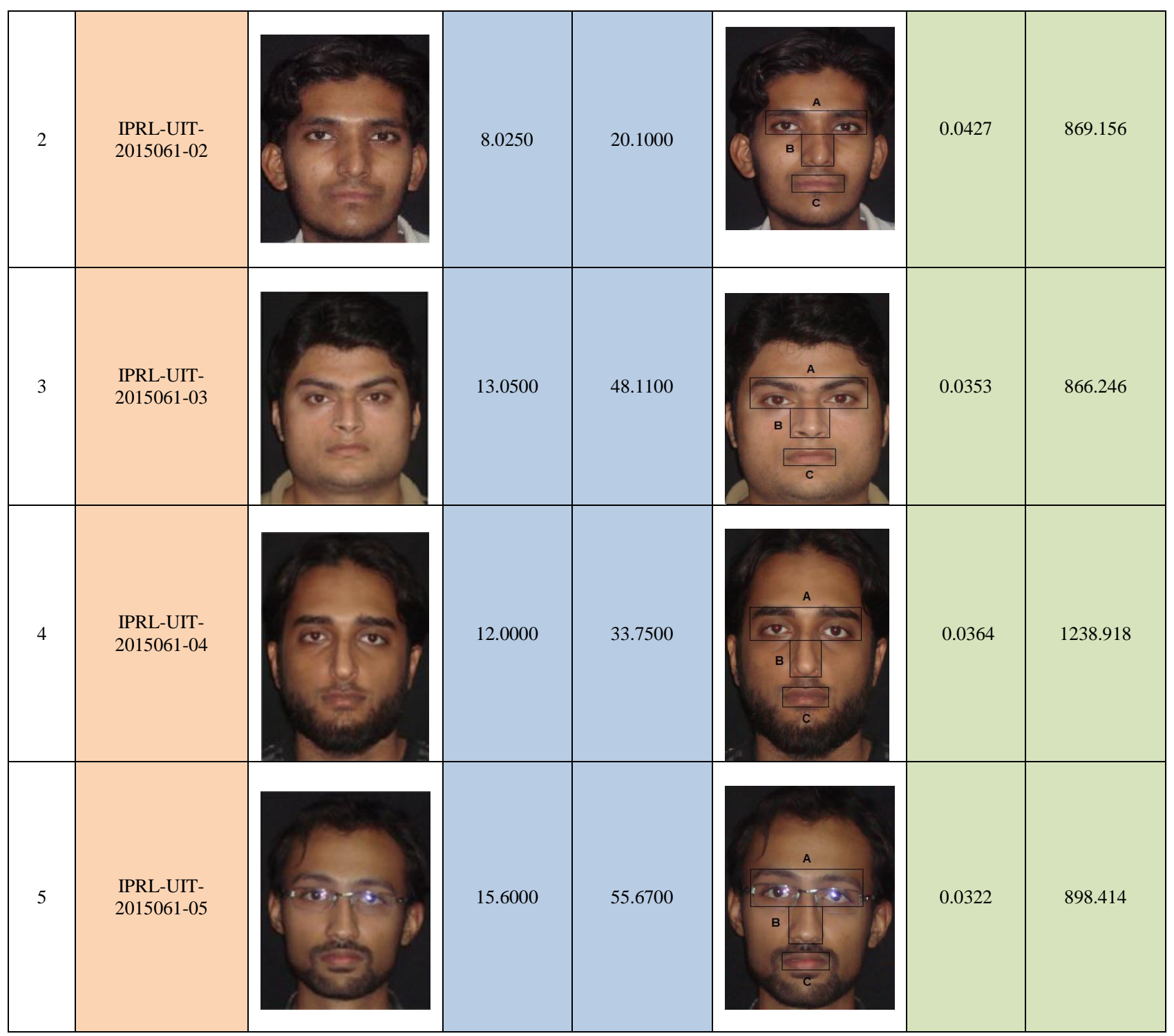

\begin{abstract}
Mean $=\mathrm{M}=\left(\kappa_{1}+\kappa_{2}\right) / 2$
Gaussian $=\mathrm{G}=\kappa_{1} \times \kappa_{2}$
\end{abstract}

In our test run, 100 faces have been tested in IPRL using dotted Raster-stereography and feature-based techniques. For dotted raster-stereography, 95 faces were correctly recognized. Using feature-based technique, 82 faces were correctly recognized. Table IV shows the facts recorded during test runs for dotted Raster-stereography and feature-based systems.

Table VI shows the results of recognition rate, training and testing time of both the techniques using IPRL database. Runtime of image normalization and alignment excludes the training and testing times.

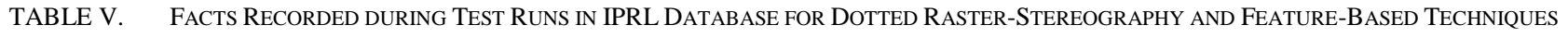

\begin{tabular}{|l|c|c|c|c|}
\hline \multicolumn{1}{|c|}{ Parameters } & $\begin{array}{c}\text { Dotted Raster- } \\
\text { stereography }\end{array}$ & $\begin{array}{c}\text { Feature- } \\
\text { Based }\end{array}$ & $\begin{array}{c}\text { Parameters } \\
\begin{array}{c}\text { Dotted Raster- } \\
\text { stereography } \\
(\%)\end{array}\end{array}$ & $\begin{array}{c}\text { Feature- } \\
\text { Based } \\
(\%)\end{array}$ \\
\hline $\begin{array}{l}\text { Number of true positive } \\
(T P)\end{array}$ & 95 & 82 & Accuracy $=\frac{T P+T N}{T P+F P+F N+T N}$ & 86.00 \\
\hline $\begin{array}{l}\text { Number of true negative } \\
(T N)\end{array}$ & 01 & 6 & Precision $=\frac{T P}{T P+F P}$ & 96.93 \\
\hline $\begin{array}{l}\text { Number of false positive } \\
(F P)\end{array}$ & 03 & 8 & Sensitivity $=\frac{T P}{T P+F N}$ & 91.11 \\
\hline
\end{tabular}




\begin{tabular}{|c|c|c|c|c|c|}
\hline $\begin{array}{l}\text { Number of false negative } \\
(F N)\end{array}$ & 01 & 4 & Specificity $=\frac{T N}{F P+T N}$ & 25.00 \\
\hline- & - & - & Positive predictive value & 42.85 \\
\hline- & - & - & Negative predictive value & 96.93 \\
& & & & $\frac{T P}{F N+T N}$ & 51.11 \\
\end{tabular}

TABLE VI. RECOGNITION RATE AND TRAINING \& TESTING TIMES FOR BOTH TECHNIQUES

\begin{tabular}{|l|l|l|l|}
\hline Technique & $\begin{array}{l}\text { Recognition } \\
\text { Rate }\end{array}$ & $\begin{array}{l}\text { Training Time } \\
\text { (second) }\end{array}$ & $\begin{array}{l}\text { Testing Time } \\
\text { (second) }\end{array}$ \\
\hline $\begin{array}{l}\text { Dotted Raster- } \\
\text { stereography }\end{array}$ & $96.00 \%$ & 260.5 & 2.1 \\
\hline Feature-Based & $88.00 \%$ & 70 & 1.2 \\
\hline
\end{tabular}

\section{CONCLUSIONS}

Each of Dotted Raster-stereography and feature based techniques was tested for 100 faces in Image Processing Research Laboratory, using IPRL database. In case of dotted Raster-stereography technique, following values of performance measures were found: accuracy $96.00 \%$, precision $96.93 \%$, sensitivity $98.95 \%$ and specificity $25.00 \%$. For feature-based technique, the same measured values were: accuracy $88.00 \%$, precision $91.11 \%$, sensitivity $95.34 \%$ and specificity $42.85 \%$. Consequently, Dotted Raster-stereography technique is a better approach for face recognition as far as these performance measures are concerned. Feature-based technique is faster in terms of the training and testing times required. Thus overall, such sensitive applications where high face recognition accuracy is required, dotted rasterstereography should be preferred. On the other hand, such applications where volume of face recognition work is large and high speed is required with some compromise in accuracy being acceptable, then feature-based technique may also be the technique of choice.

\section{REFERENCES}

[1] Delac, Kresimir, and Mislav Grgic. "A survey of biometric recognition methods." Electronics in Marine, 2004. Proceedings Elmar 2004. 46th International Symposium. IEEE, 2004.

[2] Tistarelli, M. and E. Grosso (1997). Active face recognition with a hybrid approach. Pattern Recognition Letters, 18: 933-946.

[3] Cappelli, Raffaele, Matteo Ferrara, and Davide Maltoni. "Minutia cylinder-code: A new representation and matching technique for fingerprint recognition." IEEE Transactions on Pattern Analysis and Machine Intelligence 32.12 (2010): 2128-2141.

[4] Bulatov, Yaroslav, et al. "Hand recognition using geometric classifiers." Biometric Authentication. Springer, Berlin, Heidelberg, 2004. 753-759.

[5] Lim, Shinyoung, et al. "Efficient iris recognition through improvement of feature vector and classifier." ETRI journal23.2 (2001): 61-70.

[6] Ali, Jafar MH, and Aboul Ella Hassanien. "An iris recognition system to enhance e-security environment based on wavelet theory." AMOAdvanced Modeling and Optimization 5.2 (2003): 93-104.

[7] Ko, Teddy. "A survey on behavior analysis in video surveillance for homeland security applications." Applied Imagery Pattern Recognition Workshop, 2008. AIPR'08. 37th IEEE. IEEE, 2008.

[8] Wasim, M. and Shaikh A. Book on "Raster-stereography based partial face recognition". Lambert Academic Publishing (2014).
[9] Vilas H. Gaidhane, Yogesh V. Hote, Vijander Singh. "An efficient approach for face recognition based on common eigenvalues". Pattern Recognition 47 (2014) 1869-1879. Elsevier.

[10] Jafri, R. and Arabnia, H. R. 2009. A survey of face recognition techniques. Journal of information processing system, 5 (2), 41-68.

[11] Bruner, I. S. and Tagiuri., 1954. The perception of people. In Handbook of Social Psychology, Vol. 2, G. Lindzey, Ed., Addison-Wesley, Reading, MA, 634-654.

[12] Bledsoe, W. W., 1964. The model method in facial recognition. Tech. rep. PRI:15, Panoramic research Inc., Palo Alto, CA.

[13] Kelly, M. D. 1970. Visual identification of people by computer. Tech. rep. AI-130, Stanford AI Project, Stanford, CA.

[14] Kanade, T., 1973. Computer recognition of human faces. Birkhauser, Basel, Switzerland, and Stuttgart, Germany.

[15] Darwin, C., 1972. The Expression of the Emotions in Man and Animals. John Murray, London,U.K.

[16] Galton, F., 1988. Personal identification and description. Nature, (June 21), 173-188.

[17] Kirby, M., and Sirovich, L. 1990. Application of the Karhunen-Loeve procedure for the characterization of human faces. IEEE Trans. Patt. Anal. Mach. Intell. 12.

[18] Turk, M., and Pentland, A. 1991. Eigenfaces for recognition. J. Cogn. Neurosci. 3, 72-86.

[19] Belhumeur, P. N., Hespanha, J. P., and Kriegman, D. J. 1997. Eigenfaces vs. Fisherfaces: Recognition using class specific linear projection. IEEE Trans. Patt. Anal. Mach. Intell. 19, 711-720.

[20] Etemad, K. and Chellappa, R. 1997. Discriminant analysis for recognition of human face images. J. Opt. Soc. Am. A 14, 1724-1733.

[21] Zhao,W., Chellappa, R., and Krishnaswamy, A. 1998. Discriminant analysis of principal components for face recognition. In Proceedings, International Conference on Automatic Face and Gesture Recognition. 336-341.

[22] Wiskott, L., Fellous, J.-M., and Von Der Malsburg, C. 1997. Face recognition by elastic bunch graph matching. IEEE Trans. Patt. Anal. Mach. Intell. 19, 775-779.

[23] Cox, I. J., Ghosn, J., and Yianilos, P. N. 1996. Feature-based face recognition using mixturedistance. In Proceedings, IEEE Conference on Computer Vision and Pattern Recognition. 209-216.

[24] $\mathrm{Lu}, \mathrm{Ke}$, et al. "Video-based face recognition." Image and Signal Processing (CISP), 2010 3rd International Congress on. Vol. 1. IEEE, 2010.

[25] Yi Sun, Xiaogang Wang \& Xiaoou Tang. Deep Learning Face Representation from Predicting 10,000 Classes. IEEE Conference on Computer Vision and Pattern Recognition, 2014.

[26] Junlin Hu1, Jiwen Lu, Yap-Peng Tan. Discriminative Deep Metric Learning for Face Verification in theWild. IEEE Conference on Computer Vision and Pattern Recognition, 2014.

[27] Z. Cui, W. Li, D. Xu, S. Shan, and X. Chen. Fusing robust face region descriptors via multiple metric learning for face recognition in the wild. In CVPR, pages 3554-3561, 2013.

[28] M. Guillaumin, J. Verbeek, and C. Schmid. Metric learning approaches for face identification. In ICCV, pages 498-505, 2009.

[29] G. B. Huang, H. Lee, and E. G. Learned-Miller. Learning hierarchical representations for face verification with convolutional deep belief networks. In CVPR, pages 2518-2525, 2012. 
[30] K. Simonyan, O. M. Parkhi, A. Vedaldi, and A. Zisserman. Fisher vector faces in the wild. In BMVC, 2013.

[31] L. Wolf, T. Hassner, and I. Maoz. Face recognition in unconstrained videos with matched background similarity. In CVPR, pages 529-534, 2011.

[32] L. Wolf and N. Levy. The svm-minus similarity score for video face recognition. In CVPR, pages 3523-3530, 2013.

[33] Can-Yi Lu, Hai Min, Jie Gui, Lin Zhu \& Ying-Ke Lei. Face recognition via Weighted Sparse Representation. J. Vis. Commun. Image R. 24, 111-116, Elsevier, 2013.

[34] J. Wright, A.Y. Yang, A. Ganesh, S.S. Sastry, Y. Ma. Robust face recognition via sparse representation. IEEE Transactions on Pattern Analysis and Machine Intelligence 31, 210-227, 2009.

[35] Kathryn Bonnen, Brendan F. Klare, Anil K. Jain. Component-Based
Representation in Automated Face Recognition. IEEE transactions on information forensics and security, vol. 8, no. 1, 2013.

[36] Yong Xu, Xiaozhao Fang, Xuelong Li, Jiang Yang, Jane You, Hong Liu, Shaohua Teng. Data Uncertainty in Face Recognition. IEEE transactions on cybernetics, vol. 44, no. 10, 2014.

[37] Wasim M., Kamal S. A., Shaikh A., A Security System Employing Edge-Based Raster-stereography. Int. j. biol. biotech. 10(4): 483-501, 2013.

[38] Reza Moradi Rad, Abdolrahaman Attar, Reza Ebrahimi Atani. A Robust Face Recognition Method Using Edge-Based Features. IEEE symposium on computers \& informatics, 2012.

[39] W. Frobin, E.Hierholzer, B. Drerup. Shape Analysis of Surfaces: Extraction of Shape from Coordinate Data. Moiré Fringe Topography, Gustav, Stuttgart, New York, 1983. 